\title{
The Endolysosomal System in Cell Death and Survival
}

\author{
Urška Repnik ${ }^{1}$, Maruša Hafner Česen ${ }^{1}$, and Boris Turk ${ }^{1,2}$ \\ ${ }^{1}$ Department of Biochemistry and Molecular and Structural Biology, J. Stefan Institute, Jamova 39, \\ SI-1000 Ljubljana, Slovenia \\ ${ }^{2}$ Center of Excellence CIPKEBIP, Ljubljana, Slovenia \\ Correspondence: boris.turk@ijs.si
}

The endocytic pathway is a system specialized for the uptake of compounds from the cell microenvironment for their degradation. It contains an arsenal of hydrolases, including proteases, which are normally enclosed in membrane-bound organelles, but if released to the cytosol can initiate apoptosis signaling pathways. Endogenous and exogenous compounds have been identified that can mediate destabilization of lysosomal membranes, and it was shown that lysosomal proteases are not only able to initiate apoptotic signaling but can also amplify the apoptotic pathways initiated in other cellular compartments. The endocytic pathway also receives cargo destined for degradation via the autophagic pathway. By recycling energy and biosynthetic substrates, and by degrading damaged organelles and molecules, the endocytic system assists the autophagic system in resisting apoptotic stimuli. Steps leading to lysosomal membrane permeabilization and subsequent triggering of cell death as well as the therapeutic potential of intervention in lysosomal membrane permeabilization will be discussed.

Since the discovery of lysosomes in 1950s (de SDuve et al. 1955), the concept of the endocytic pathway has changed. Although there has been huge progress in understanding the molecular mechanisms of targeting and fusion of organelles, several conceptual dilemmas have not been completely resolved. The primary function of the endocytic pathway is bulk degradation and recycling of the internalized material and redundant cellular components. Over the years, additional functions have been associated with it. Endosomes and lysosomes can fuse with the plasma membrane to repair it and to release the accumulated nondegradable material
(Medina et al. 2011). Intraluminal vesicles are the source of exosomes, which have multiple functions, especially for the immune system (Ludwig and Giebel 2012). Endosomes have numerous functions in fighting infections: they can signal the presence of pathogens through Toll-like receptors, they are the site of antigenic peptide generation and their assembly with major histocompatibility complex class II molecules, and they can also kill residing pathogens (Gruenberg and van der Goot 2006). Because of a high content of proteases, de Duve (1959) coined the figurative term "suicide bags" for lysosomes, a concept since supported by a

Editors: Eric H. Baehrecke, Douglas R. Green, Sally Kornbluth, and Guy S. Salvesen

Additional Perspectives on Cell Survival and Cell Death available at www.cshperspectives.org

Copyright (C) 2013 Cold Spring Harbor Laboratory Press; all rights reserved; doi: 10.1101/cshperspect.a008755

Cite this article as Cold Spring Harb Perspect Biol 2013;5:a008755 
U. Repnik et al.

wealth of experimental reports (de Duve 1959). Perhaps the best examples of this concept are natural killer cells and cytotoxic T cells. Both have specialized lysosome-related organelles, secretory granules, that contain perforin and granzyme B, which can mediate apoptosis in the target cell (Blott and Griffiths 2002; Trapani and Smyth 2002). However, every cell can potentially become a victim of its own lysosomal hydrolases, especially if lysosomal membranes are destabilized so that the enzymes can escape into the cytosol. These offer great potential to exploit scenarios for therapy for certain diseases, most importantly cancer. On the other hand, by enabling degradation of the material sequestered by autophagy, the endocytic pathway can assist autophagy in counteracting apoptosis when cells are challenged with an apoptotic stimulus (Repnik and Turk 2010; Hafner Česen et al. 2012; Repnik et al. 2012).

\section{ENDOCYTIC PATHWAY}

Whenever we talk about lysosomes in the context of cell death and survival, we should more accurately refer also to other organelles of the endocytic pathway (see below for details; Fig. 1). Understanding the biology of the endocytic pathway is a prerequisite for the understanding of its role in the processes of cell death and survival.

We favor the concept proposed by Griffiths in 1996 that the endocytic pathway involves stable compartments connected by vesicular traffic as opposed to the maturation model, which implies that organelles are formed de novo and mature into the next organelle along the endocytic pathway. Griffiths defines a compartment as a complex, multifunctional membrane organelle that is specialized for a particular set of essential functions for the cell. According to this hypothesis, compartments cannot be assembled de novo, but arise only once during evolution and must be transferred from the mother cell to daughter cells during mitosis. In contrast, vesicles are considered to be transient organelles, simpler in composition, and are defined as membrane-enclosed containers that form de novo by budding from a preexisting compart- ment. Compartments can undergo homotypic fusion with themselves, whereas vesicles cannot fuse with themselves but only with a preexisting compartment. In contrast to compartments, vesicles can undergo maturation, which is a physiologically irreversible series of biochemical changes such that the particle develops into a biochemically different end stage. According to this hypothesis, early endosomes and late endosomes represent stable compartments in the endocytic pathway, while primary endocytic vesicles, phagosomes, multivesicular bodies (MVBs) or endosome carrier vesicles (ECVs), secretory granules, and even lysosomes represent vesicles (Griffiths 1996).

Endocytosis is an entrance route to the cell and is important for the uptake of nutrients, recycling of the plasma membrane, and surveillance of the extracellular environment. From the functional point of view, the endocytic pathway can be divided into the recycling circuit for the plasma membrane and its components, the degradative system for the degradation of molecules, and the connecting system for the transport of degradation-destined cargo from the early recycling circuit to the degradative system (Huotari and Helenius 2011). In Figure 1, the endocytic pathway is schematically presented (Griffiths 1996; Luzio et al. 2000; Eskelinen et al. 2011). The endocytic vesicle, which arises at the plasma membrane, most prominently from clathrin-coated pits and vesicles, first fuses with the early endosome, which is a major sorting compartment. A large part of the cargo and membranes internalized are recycled back to the plasma membrane through the recycling vesicles. Components that should be degraded are transported to the late endosome via MVBs, also referred to as ECVs. They are spherical vesicles and contain many small, membrane-enclosed intraluminal vesicles (ILVs). The formation of ILVs involves inward budding of the limiting membrane containing transmembrane ubiquitinated proteins and is regulated by ESCRT (endosomal sorting complex required for transport) machinery (Mayers and Audhya 2012). ILVs are present already in early endosomes and become particularly numerous in MVB/ ECV, late endosomes, and hybrid organelles. 


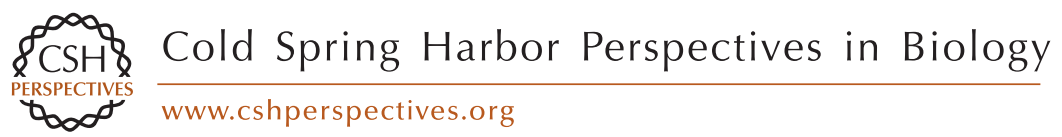

A

Autophagic pathway

-Chaperone-mediated autophagy

-Microautophagy

Autophagosome
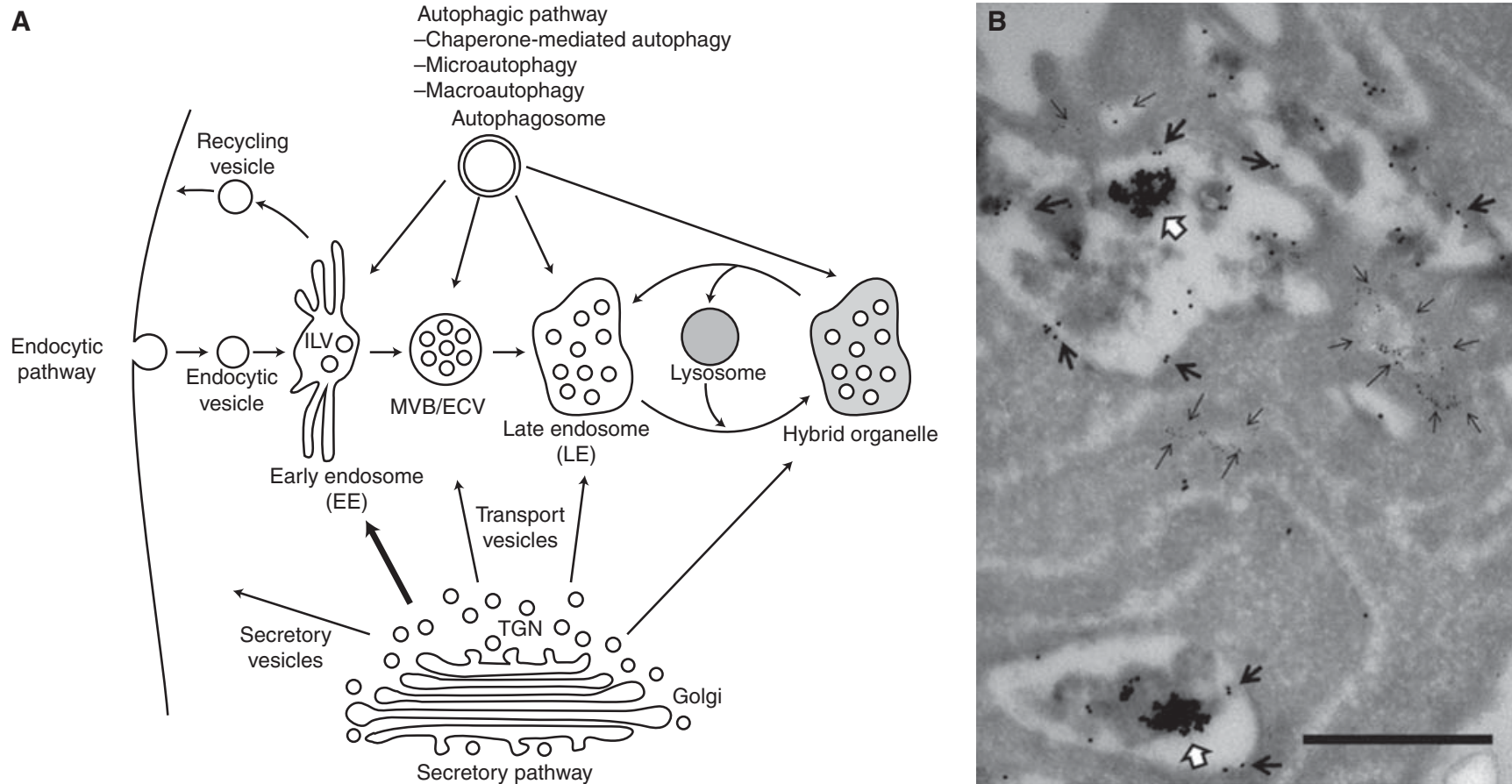

Figure 1. Endocytic pathway. (A) A schematic representation of the endocytic pathway (details are explained in the text). EE, early endosome; ILV, intraluminal vesicle; MVB, multivesicular body; ECV, endosome carrier vesicle; LE, late endosome; TGN, trans-Golgi network. (B) A transmission electron micrograph showing endocytic organelles in RAW cells, labeled with three different sizes of gold particles. Cells were pulsed with a 15-nm gold-bovine serum albumin (BSA) conjugate (block arrows) for $4 \mathrm{~h}$ and chased for $24 \mathrm{~h}$ to label LEs. During the last $6 \mathrm{~min}$ of culture, cells were fed with a 5-nm gold-BSA conjugate (thin arrows) to label endocytic vesicles and EEs. A thin Tokuyasu section was labeled with anti-LAMP2 antibody in a three-step reaction involving the primary antibody, a secondary rabbit anti-mouse antibody, and a 10-nm goldprotein A conjugate (thick arrows). Scale bar, $500 \mathrm{~nm}$. 
U. Repnik et al.

The late endosome represents the stomach of the cell. The enzymes needed for degradation are delivered by transport vesicles from the trans-Golgi network (TGN) to early and late endosomes. Most lysosomal hydrolases, including the proteases named cathepsins, acquire mannose 6-phospate during their transport through the Golgi complex and are recognized by mannose phosphate receptors in the TGN. In addition, some hydrolases, like sphingomyelinase, can use sortilin as an alternative sorting receptor (Saftig and Klumperman 2009). Arguably, lysosomes are vesicles that can store mature lysosomal enzymes and deliver them to a late endosomal compartment when needed. The resulting organelle is called the hybrid organelle or endolysosome. Lysosomes bud off the hybrid organelle in a process referred to as lysosome re-formation (Bright et al. 1997). It has recently been shown that lysosome re-formation depends on mTOR activation, which in turn depends on monomeric metabolites, which are produced during lysosomal degradation (Yu et al. 2010). It seems likely that lysosome re-formation serves to redistribute lysosomal enzymes (Griffiths 1996; Tjelle et al. 1996). It is also possible that for some enzymes transient escape from the harsh environment of late endosomes prolongs their stability.

Although the bulk of acid hydrolases have been localized in the lysosomes and not in the late endosomes, the latter are the main degradative compartment of the cell (Tjelle et al. 1996). More than 50 different hydrolases, including proteases, phosphatases, nucleases, glycosidases, sulphatases, lipases, etc., and some activator proteins that assist the hydrolysis of substrates, such as (pro)saposins, have been thus identified in these organelles. The luminal conditions of $\mathrm{pH}$ and perhaps the redox potential within the late endolysosomal system are designed to denature protein substrates and thereby make them susceptible to enzymatic degradation (Pillay et al. 2002). The $\mathrm{pH}$ thus decreases along the endocytic pathway: early endosomes have a $\mathrm{pH}$ between 6.8 and 6.1, late endosomes have a $\mathrm{pH}$ in the range of $6.0-$ 4.8 , and in lysosomes the $\mathrm{pH}$ can decrease to 4.5 (Maxfield and Yamashiro 1987). Because some lysosomal enzymes have $\mathrm{pH}$ optima in the neutral to alkaline range, it was suggested that the $\mathrm{pH}$ in lysosomes may actually fluctuate over a wider range, with a preference for a more acidic state (Butor et al. 1995). The role of redox potential inside lysosomes is more controversial. Initially it was proposed that it is reducing (Pillay et al. 2002); however, recent findings have shown that it is oxidizing and comparable to the endoplasmic reticulum (Austin et al. 2005).

In the limiting membrane there are transport proteins, which enable the translocation of ions or small metabolites into the cytosol. The integral membrane proteins also include structural glycoproteins LAMP (lysosome-associated membrane protein)-1, LAMP-2, CD63, and LIMP-2 (Schroder et al. 2010). LAMP isoforms are among the most abundant lysosomal proteins. They have large luminal domains, which are heavily glycosylated to protect the protein scaffold from the lysosomal enzymes. Although it was suggested that they provide structural integrity to the lysosomal membrane by forming a continuous protective carbohydrate lining along its inner leaflet, this idea lacks experimental support (Kundra and Kornfeld 1999). LAMPs have only short cytoplasmic tails, which are involved in vesicle trafficking along the microtubules (Huynh et al. 2007) and serve as receptors for chaperone-mediated autophagy (Cuervo and Dice 1996).

Late endosomes, lysosomes, and hybrid organelles are extremely dynamic organelles, and distinction between them is often difficult, even with electron microscopy analysis of immunolabeled thin sections, in particular in certain cell types including RAW and J774 macrophage cell lines and HeLa cells (Griffiths 1996). So far, specific markers for lysosomes that are absent in late endosomes have not been identified. LAMP molecules and acid hydrolases are found in both late endosomes and lysosomes. However, cation-independent mannose phosphate receptor (CI-MPR), Rab7, and the regulatory (RII) domain of the cAMP-dependent protein kinase are present only on late endosomes but not on lysosomes, offering some possibility for discrimination (Griffiths et al. 1988, 1990a,b; Tjelle et al. 1996). In electron micrographs late 
endosomes contain many ILV and membrane fragments, whereas lysosomes appear electron dense, rather homogeneous, and with fewer membrane fragments (Tjelle et al. 1996; Huotari and Helenius 2011); however, their discrimination is still not an easy task.

The degradative system of the endocytic pathway receives input for degradation not only from the cell microenvironment via endocytosis and phagocytosis, but also from the cell itself via the autophagic pathway. There are three main forms of autophagy: macroautophagy, characterized by the formation of double-membrane autophagosomes; chaperone-mediated autophagy, which depends on transmembrane receptors in the endosome/lysosome limiting membrane; and microautophagy, which includes internalization by invagination of the endosomal/lysosomal membrane (Cuervo 2004). Although it is often described that autophagosomes fuse with lysosomes, it has actually been shown that autophagosomes fuse with a LAMPpositive compartment before they acquire lysosomal proteases. It therefore seems likely that autophagosomes can enter the endocytic pathway at multiple stages, including early endosome, $\mathrm{MVB} / \mathrm{ECV}$, and, in particular, late endosomes and hybrid organelles (Fig. 1) (Eskelinen et al. 2011).

Of all lysosomal components, lysosomal proteases seem to be the main effector molecules that interface with the apoptotic machinery, if released into the cytosol. To initiate the lysosomal pathway of apoptosis, the degradative part of the endocytic pathway must therefore be targeted, which, however, includes not only lysosomes but also late endosomes and hybrid organelles, endolysosomes. Some hydrolases, particularly those with $\mathrm{pH}$ optima close to neutral, may be active already in the early endosomes. Most of the compounds that have lysosomal membrane-destabilizing properties, for example, lysosomotropic detergents, cannot specifically target a particular organelle, because differences in $\mathrm{pH}$ are too small (Fig. 2). Consequently, targeting the complex endolysosomal system will result in complex and often diverse cell responses. Therefore, we would like to emphasize that the use of the term "lyso- some" is too narrow, as the complete degradative system of the endocytic pathway, which includes late endosomes, lysosomes, and hybrid organelles, harbors an arsenal of proteases that can initiate apoptotic signaling pathways if released into the cytosol. A more accurate alternative for the term "lysosome" is the term "endolysosomal system"; it also implies the inherent complexity of the system.

\section{THE ROLE OF LYSOSOMES IN CELL DEATH}

Apoptosis is the most investigated form of cell death and is characterized by caspase activation, chromatin condensation, nuclear fragmentation, and formation of apoptotic bodies. Alternative forms of cell death include necrosis, necroptosis, and secondary necrosis, which manifest with cytoplasmic swelling (oncosis), dilated organelles, loss of plasma membrane integrity, and the absence of caspase activation and chromatin condensation (Vanlangenakker et al. 2008; Vanden Berghe et al. 2010). Although necrosis has long been considered accidental and uncontrolled, it is now considered to be a wellorchestrated form of cell demise (Yamashima 2012). In necroptosis and secondary necrosis, lysosomal membrane permeabilization (LMP) is a late process, which coincides with the cellular disintegration phase and may, through proteolysis, contribute to the generation of modified damage-associated molecular patterns, which activate the immune system (Vanden Berghe et al. 2010). At least in some forms of necrosis, LMP is an early event that determines the necrotic cell death as a result of massive release of hydrolases (Yamashima 2012). However, LMP can also initiate or amplify apoptotic signaling. A quantitative relationship between the amount of lysosomal rupture and the mode of cell death has been suggested to explain different cell death pathways following LMP, so that moderate insults trigger a limited release of lysosomal contents into the cytosol and lead to apoptosis, whereas strong insults result in a complete release of lysosomal contents and lead to necrosis (Kagedal et al. 2001; Turk and Turk 2009).

Apoptotic cell death is mediated through two main signaling pathways: the extrinsic or 


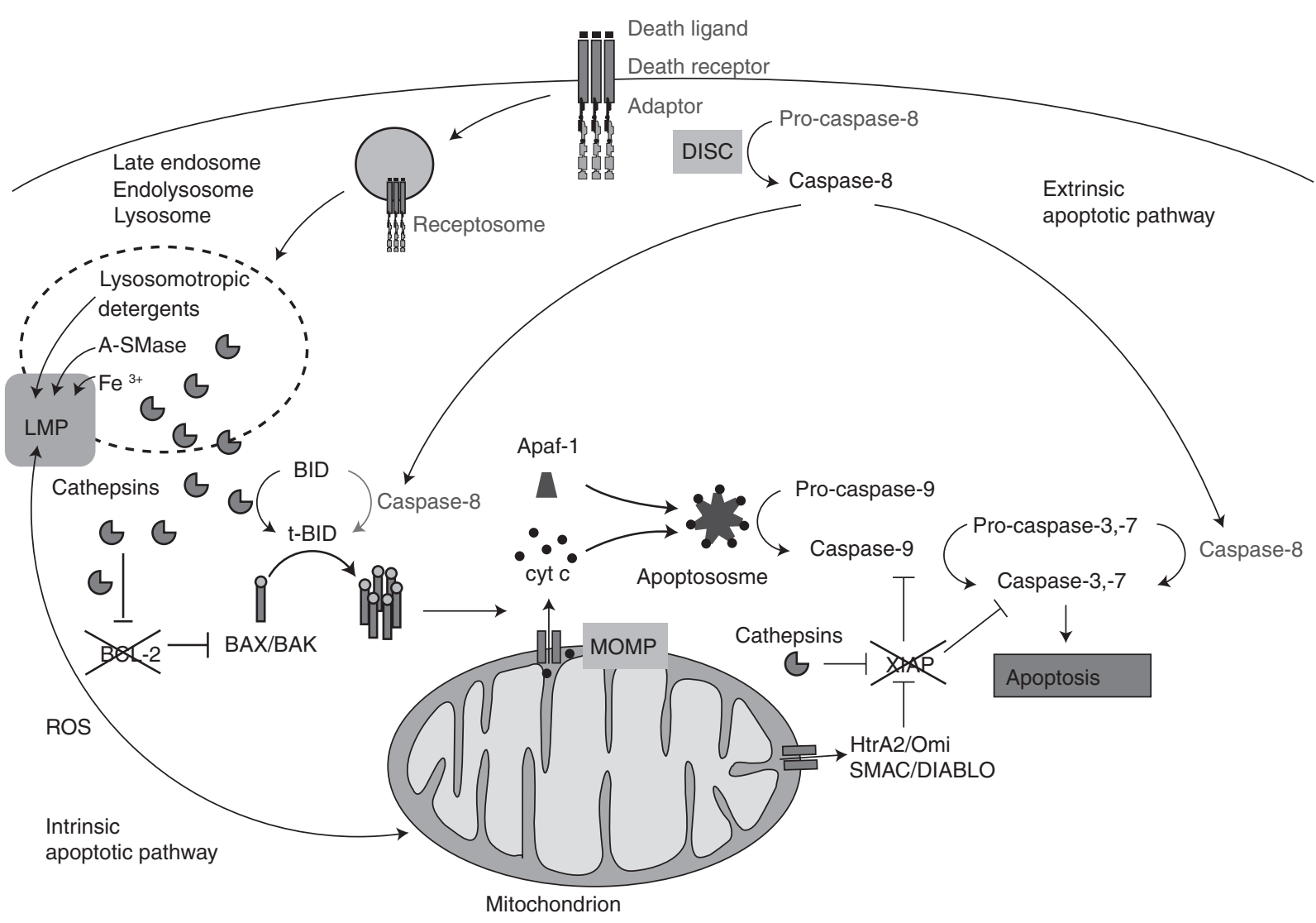

Figure 2. The role of lysosomes in apoptosis. Lysosomotropic detergents, reactive oxygen species (ROS), acid sphingomyelinase (A-SMase), Fenton reaction, etc., can trigger lysosomal membrane permeabilization (LMP), during which lysosomal contents are released into the cytosol. Cathepsins can process BID and degrade antiapoptotic BCL-2 proteins, which together enable the oligomerization of $\mathrm{BAX}$ and $\mathrm{BAK}$ proteins into mitochondrion membrane-spanning pores, causing mitochondrial outer membrane permeabilization (MOMP) and subsequent caspase activation. Cathepsins can degrade inhibitors of caspases, such as XIAP, further promoting caspase activation downstream of MOMP, along with XIAP antagonists SMAC/DIABLO and HtrA2/Omi. The extrinsic apoptotic pathway is represented with gray lines and text. 
Lysosomes in Apoptosis

death receptor pathway, which is induced upon ligation of transmembrane death receptors by their specific ligands; and the intrinsic or mitochondrial pathway, the induction of which involves nonreceptor stimuli, such as metabolic stress, UV radiation, and DNA damage. It has been proposed that LMP can trigger the intrinsic apoptotic pathway through a sequence of events known as the lysosomal apoptotic pathway (Cirman et al. 2004; Droga-Mazovec et al. 2008; Repnik and Turk 2010; Melo et al. 2011). With increased understanding of its molecular mechanisms, the lysosomal pathway of apoptosis has been recognized as a therapeutic target (Groth-Pedersen and Jaattela 2010; Repnik et al. 2012).

Lysosomal Pathway of Apoptosis

Lysosomal Cathepsins - Initiator Proteases of the Lysosomal Pathway of Apoptosis

Lysosomal proteases, especially cathepsins, have been identified as the main promoters of the lysosomal apoptotic pathway, which can be initiated upon LMP. Lysosomal cathepsins are either cysteine proteases (B, C, F, H, L, O, S, V, $\mathrm{X}$ ) or aspartic proteases (D). They are predominantly endopeptidases, although cathepsins $\mathrm{B}$ and $\mathrm{H}$ can also act as exopeptidases, whereas cathepsins $\mathrm{C}$ and $\mathrm{X}$ are exopeptidases only. The expression of some, such as cathepsins $\mathrm{S}$ and $\mathrm{K}$, is tissue- and cell-type-specific, whereas the others are expressed ubiquitously. They are rather nonspecific proteases, generally cleaving their substrates after hydrophobic or basic residues (Turk et al. 2002; Conus and Simon 2008; Turk and Turk 2009). Normally, cathepsins are enclosed inside the lysosomes, where they carry out nonspecific bulk proteolysis of proteins that have been destabilized by low $\mathrm{pH}$. However, if released into the cytosol, the same proteases can perform rather specific cleavages of proteins in their native conformation, during the brief period of time before they succumb to the more neutral $\mathrm{pH}$ conditions of the cytosol (Turk and Turk 2009; Turk et al. 2012). Some of the target molecules for cysteine cathepsins in the cytosol have been identified, and they are involved in apoptotic signaling (Stoka et al. 2001; Cirman et al. 2004; Blomgran et al. 2007; Droga-Mazovec et al. 2008).

\section{LMP - the Initiation Phase}

LMP, which is a point of no return in the lysosomal apoptotic pathway, is often an early event and thus crucial for the induction of cell death, preceding other executioners, such as caspases or mitochondrial outer membrane permeabilization (MOMP). It is also critical for the release of cysteine cathepsins from lysosomes. However, one should be aware that LMP is a nonproteolytic event (Turk et al. 2012). Recently, provoking cathepsin-mediated cytotoxicity by directly targeting lysosomes of cancer cells with lysosomotropic agents has been recognized for its therapeutic potential. There are a number of different chemotherapeutic agents that induce LMP (Groth-Pedersen and Jaattela 2010; Kreuzaler and Watson 2012). The best characterized are the lysosomotropics (de Duve et al. 1974), which are lipophilic bases that after protonation become trapped in acidic vesicles, where they accumulate and develop membranolytic properties, thereby releasing lysosomal content in the cytosol (Miller et al. 1983). Among the synthetic agents, one of the most studied is the amino acid methyl ester LeuLeuOMe (Cirman et al. 2004; Droga-Mazovec et al. 2008), which triggers LMP only after it is polymerized into the hydrophobic chains of at least three dipeptide units by cathepsin C (Thiele and Lipsky 1990). LeuLeuOMe is already in clinical trials for treatment of graft-versus-host disease during allogeneic bone marrow transplantation (Filicko-O'Hara et al. 2009). However, there are also other lysosomotropics, such as amine hydroxychloroquine (Boya et al. 2003b), detergents $N$-dodecylimidazole (Wilson et al. 1987) and O-methylserine dodecylamide hydrochloride ( $\mathrm{Li}$ et al. 2000), and quinolone antibiotics, such as ciprofloxacin and norfloxacin, which need UV light to trigger LMP (Boya et al. 2003a). In addition, derivatives of SW43 and PB282, two classes of $\sigma 2$ receptor ligands, were shown to induce LMP in pancreatic cancer (Hornick et al. 2012).

A number of endogenous compounds are involved in LMP. Probably the most studied is 
U. Repnik et al.

the lysosomotropic sphingolipid sphingomyelin, which in lysosomal membranes is converted first to ceramide and later to sphingosine by acid sphingomyelinase (A-SMase) and ceramidase, respectively (Kronke 1999). Accumulation of sphingosine was suggested to influence the stability of the lysosomal membrane (Kagedal et al. 2001). Additional proteases suggested to be involved in LMP are the cytosolic Ca-dependent cysteine proteases, the calpains. Based on a neuronal study, Yamashima and his colleagues proposed the "calpain-cathepsin hypothesis" suggesting that in the case of increased cytosolic calcium concentration, as found in ischemiaaffected neurons, activated calpains translocate to the lysosomal membrane, where they degrade the carbonylated Hsp70.1, which causes LMP and subsequently triggers necrosis (Sahara and Yamashima 2010; Yamashima 2012). However, calpains are involved not only in necrosis but also in apoptotic cell death, in which they were shown to process BID into proapoptotic t-BID (Gil-Parrado et al. 2002). Moreover, calpains were suggested to translocate to the lysosomal membrane of epithelial cells during mammary gland involution to cleave cytosolic parts of membrane proteins, such as LAMP-2, contributing to LMP and thus triggering apoptotic cell death (Arnandis et al. 2012). In addition, it was shown that LMP in mammary epithelium is Stat3-dependent and independent of the executioner caspases caspase-3, -6, and -7. Stat 3 was found to up-regulate the expression of lysosomal cathepsins B and L, while down-regulating their endogenous inhibitor Spi2A (Kreuzaler et al. 2011). Among other endogenous molecules we also find free fatty acids, such as palmitic acid, which triggers LMP before MOMP (Almaguel et al. 2010). Kagedal et al. (2005) initially proposed that even BAK is directly involved in the LMP in staurosporine-induced apoptosis; however, this observation was later disputed (Oberle et al. 2010).

Reactive oxygen species (ROS) are another group of very potent LMP inducers. During oxidative stress a cell produces large amounts of hydrogen peroxide, which can in lysosomes react with ferruginous material delivered there mostly by the autophagic pathway. In a series of Fenton-type reactions, highly reactive hydroxyl radicals are produced, causing peroxidation of membrane lipids, leading to LMP. Therefore, the oxidative stress that has started in the mitochondrial respiratory chain is amplified through the Fenton reactions within lysosomes (Terman et al. 2006; Kurz et al. 2007). In addition, lysosomal enzymes have been suggested to promote mitochondrial ROS production, creating another feedback loop to amplify the signal (Zhao et al. 2003). However, LMP can also be triggered directly by low concentrations of exogenous hydrogen peroxide (Ishisaka et al. 2002; Lin et al. 2010) or by the ROS-generating photosensor $N$-aspartyl chlorin e6 (Liu et al. 2011). Zhao et al. (2001) suggested that short stimulation with hydrogen peroxide could also trigger LMP indirectly by activation of phospholipase A2, leading to degradation of membrane phospholipids. Importantly, several stimuli, such as the aminoglycoside antibiotic gentamicin (Denamur et al. 2011), the $\sigma 2$ receptor ligand siramesine (Ostenfeld et al. 2005), and the widely used chemotherapeutic agent cisplatin (Pourahmad et al. 2010), were also linked to increased ROS production, leading to LMP. Finally, oxidative stress and ROS-dependent LMP were suggested to be especially important in the aging of postmitotic cells (Kurz et al. 2007).

Other stimuli, such as various toxins, for example, the lethal toxin from Bacillus anthracis (Averette et al. 2009), leukotoxin from the oral bacterium Aggregatibacter actinomycetemcomitans (DiFranco et al. 2012), cytotoxins from cobra venom (Feofanov et al. 2005), and even crotamine, one of the toxic components of the rattlesnake Crotalus durissus terrificus venom, were also shown to induce LMP, leading to apoptosis (Hayashi et al. 2008). It is worth mentioning that the cytotoxicity of various natural compounds toward cancer cells is being investigated more intensively and is considered a very promising approach in combating cancer. It was reported that curcumin, a spice and a member of the ginger family, triggers LMP and subsequent cell death in A549 lung carcinoma cells (Chen et al. 2012). Moreover, a derivative of betulinic acid, found in the bark of several 
species of plants (Gonzalez et al. 2012), and sulforaphane (Rudolf and Cervinka 2011), found in cruciferous vegetables such as broccoli and cauliflower, are also capable of inducing LMP, leading to subsequent cell death through the lysosomal apoptotic pathway.

When LMP is triggered indirectly, it may serve as an amplification loop to strengthen apoptotic signaling (Schrader et al. 2010; Repnik et al. 2012). Although recent evidence suggests that LMP also has an amplifying role in the death receptor pathway, there is still much controversy about its role, especially in tumor necrosis factor (TNF)- $\alpha$ and TNF-related apoptosis-inducing ligand (TRAIL) pathways (Hafner Česen et al. 2012). Several mechanisms have been proposed in recent years for induction of LMP in TNF- $\alpha$ and TRAIL-induced apoptosis, in which caspase- 8 plays a central role. Caspase- 8 was thus suggested to cleave caspase-9, which in turn directly induces LMP (Gyrd-Hansen et al. 2006), although how cleavage of caspase- 9 could activate this protease was not explained. Caspase- 8 was also suggested to be capable of activating A-SMase, responsible for ceramide generation, which mediates translocation of cathepsin D into cytosol (Heinrich et al. 2004). Similarly, sphingosine was suggested to regulate the activity of cathepsin B (Werneburg et al. 2002). Another suggestion was that BIM- and BAX-triggered LMP is dependent on Jun amino-terminal kinase (JNK) in TRAIL-induced apoptosis (Werneburg et al. 2007). The mechanism of the process was recently explained by the involvement of JNK in the formation of a multimeric complex for compartment-specific activation of BAX on lysosomal membranes, so-called PIXosomes, which were suggested to be responsible for LMP upstream of MOMP. PIXosomes could therefore represent a new way of communication between organelles (Werneburg et al. 2012).

Nevertheless, lysosomes are rather sturdy organelles. Understanding the triggers of LMP and identifying the endogenous inhibitors of LMP as well as the regulators of lysosome stability are of paramount importance. Recently, Kirkegaard et al. (2010) showed that a molecular chaperone, heat shock protein 70 (Hsp70), stabilizes lysosomes by binding to an essential cofactor for lysosomal sphingomyelin metabolism, endolysosomal anionic phospholipid bis(monoacylglycero) phosphate (BMP). This interaction stimulates the activity of A-SMase to convert sphingomyelin to ceramide, whose protective role remains undetermined (Horvath and Vigh 2010). The decreased levels of LAMP1 and -2 were also shown to render cells more sensitive to LMP (Fehrenbacher et al. 2008). Changes in the lipid composition of the lysosomal membrane were also suggested to influence the membrane stability. It was further suggested that increased lysosomal membrane stability due to the cholesterol accumulation attenuates cell death by apoptosis (Appelqvist et al. 2011). Finally, a study from Yue and colleagues has shown that glycosaminoglycans also protect against destabilization of the lysosomal membrane (Yue et al. 2009). However, if LMP cannot be prevented, there are intracellular cysteine protease inhibitors, such as stefin A and B and various serpins, as the last barrier that can possibly prevent cell death by blocking the cathepsins (Repnik and Turk 2010). However, despite the progress in the field of the lysosomal apoptotic pathway, the exact mechanisms of LMP and the regulation of stability of the lysosomal membrane remain elusive.

\section{The Molecular Mechanism Downstream from LMP - the Execution Phase}

The events downstream from LMP have been thoroughly studied in a model of LeuLeuOMe-induced apoptosis (Stoka et al. 2001; Cirman et al. 2004; Droga-Mazovec et al. 2008). After LMP, which enables the release of lysosomal proteases and probably some other matrix hydrolases into the cytosol, a lethal sequence of events takes place. Cathepsins cleave the BCL-2 family member BID into a proapoptotic form that promotes the oligomerization of proapoptotic BAX and BAK proteins, which in turn triggers MOMP (Stoka et al. 2001; Blomgran et al. 2007). In mouse BID, multiple cleavage sites within the bait loop were identified for cathepsins. These cleavage sites are not conserved in human BID; however, t-BID fragments of similar sizes are observed in human 
U. Repnik et al.

cells, suggesting that the cleavages by cathepsins occur at similar positions (Repnik et al. 2012). Moreover, cysteine cathepsins also proteolytically inactivate several antiapoptotic molecules, such as BCL-2, BCL-xL, and MCL-1, which enables the release and activation of BAX and BAK (Droga-Mazovec et al. 2008). Besides proteolytic processing of BCL-2 family members by the cathepsins and its effect upstream of mitochondria, cysteine cathepsins were also found to act downstream from MOMP, where they cleave the caspase-3, -7, and -9 inhibitor X-chromosomelinked inhibitor of apoptosis (XIAP) to enable executioner caspase activation (Droga-Mazovec et al. 2008). In addition, cathepsin D was found to process caspase- 8 directly in the neutrophils, which is, however, a more specific situation (Conus et al. 2008). Importantly, cathepsins not only trigger apoptosis but can also amplify the signal initiated either outside or inside the cell (Repnik et al. 2012). It is therefore likely that some new cathepsin substrates will be identified in the future (Repnik and Turk 2010).

\section{Secretory Lysosomes}

Many hematopoietic cells and also melanocytes contain unique organelles with combined functions of lysosomes and secretory granules, so-called secretory lysosomes. In addition to lysosomes, they contain specialized secretory proteins, including proteins that can trigger apoptosis in target cells. In cytotoxic T lymphocytes and natural killer cells, they are called lytic granules and contain the pore-forming protein perforin and serine proteases the granzymes (Clark and Griffiths 2003). Perforin forms pores in the membrane of the target cell, thereby enabling granzymes to enter the cell. Once inside the target cell, granzyme B triggers apoptosis either by proteolytic activation of the effector caspases, caspase- 3 and -7 , or by processing of the BID molecule (Anthony et al. 2010). Importantly, killer cells are protected against their own killing machinery by the low $\mathrm{pH}$ of granules, which prevents perforin from binding the calcium that is needed for its activity. In addition, granzymes are only poorly active at low $\mathrm{pH}$ (Bird et al. 2009). However, the high content of granzymes makes cytotoxic T lymphocytes and natural killer cells susceptible to the lysosomal pathway of apoptosis, which was exploited in the LeuLeuOMe-mediated depletion of perforin-positive $\mathrm{T}$ cells from donor lymphocyte infusion (Friedman et al. 2007; FilickoO’Hara et al. 2009).

\section{THE ROLE OF LYSOSOMES IN COUNTERACTING CELL DEATH}

Although the focus of our review has been the cell death potential of the endocytic pathway, the endocytic pathway also assists the autophagic system in resisting apoptotic cell death by degrading autophagy-delivered cargoes. It was thus shown that lysosomal dysfunction promotes neurodegeneration because it impairs constitutive autophagy (Thelen et al. 2012). In addition, it was proposed that the protective autophagic response induced by TRAIL continuously sequesters caspase- 8 in autophagosomes, but its elimination depends on the subsequent lysosomal degradation (Hou et al. 2010).

Inhibition of macroautophagy can trigger apoptosis by itself(Boya et al.2005). Rapamycin, which promotes macroautophagy, protects cells against a range of proapoptotic insults through the enhanced clearance of mitochondria, thereby reducing cytosolic cytochrome $c$ release and downstream caspase activation (Ravikumar et al. 2006). Besides macroautophagy, chaperonemediated autophagy and microautophagy can also protect cells from apoptotic insults (Wang et al. 2008). However, all forms of autophagy converge on the endocytic pathway and depend on subsequent lysosomal degradation. LMP is therefore proapoptotic not only because it allows the release of lysosomal protease into the cytosol, but also because it diminishes the degradative capacity of the endocytic system and thereby impairs the cytoprotective role of autophagy and lowers the apoptotic threshold.

\section{CONCLUDING REMARKS}

The endocytic pathway is a complex system of membrane-enclosed organelles that contain diverse hydrolases. If released into the cytosol, 
lysosomal hydrolases can contribute to apoptotic or necrotic programs of cell death, which can be initiated by internal or external stimuli. Interfering with the lysosomal pathway of apoptosis has great therapeutic potential, partially because it simultaneously destroys the endocytic degradative potential of the cells and thereby diminishes the cytoprotective role of autophagy. Although the list of LMP-inducing compounds is already long, polymer technology and nanotechnology hold prospects for multifaceted "designer" compounds, which would be more specific in terms of targeting, more efficient in terms of membrane destabilization, and whose activity would be limited to the digestive system of the endocytic pathway to minimize side effects.

\section{ACKNOWLEDGMENTS}

The work is supported by grants P1-0140, J14121, and J1-3602 from the Slovene Research Agency. We thank Gareth W. Griffiths for the discussions and careful reading of the manuscript on the endocytic pathway, and the Electron Microscopy Unit for Biological Sciences, Department of Biology, University of Oslo, Norway.

\section{REFERENCES}

Almaguel FG, Liu JW, Pacheco FJ, De Leon D, Casiano CA, De Leon M. 2010. Lipotoxicity-mediated cell dysfunction and death involve lysosomal membrane permeabilization and cathepsin L activity. Brain Res 1318: 133 143.

Anthony DA, Andrews DM, Watt SV, Trapani JA, Smyth MJ. 2010. Functional dissection of the granzyme family: Cell death and inflammation. Immunol Rev 235: 73-92.

Appelqvist H, Nilsson C, Garner B, Brown AJ, Kagedal K, Ollinger K. 2011. Attenuation of the lysosomal death pathway by lysosomal cholesterol accumulation. Am J Pathol 178: 629-639.

Arnandis T, Ferrer-Vicens I, Garcia-Trevijano ER, Miralles VJ, Garcia C, Torres L, Vina JR, Zaragoza R. 2012. Calpains mediate epithelial-cell death during mammary gland involution: Mitochondria and lysosomal destabilization. Cell Death Differ doi: 10.1038/cdd.2012.46.

Austin CD, Wen X, Gazzard L, Nelson C, Scheller RH, Scales SJ. 2005. Oxidizing potential of endosomes and lysosomes limits intracellular cleavage of disulfidebased antibody-drug conjugates. Proc Natl Acad Sci 102: 17987-17992.
Averette KM, Pratt MR, Yang Y, Bassilian S, Whitelegge JP, Loo JA, Muir TW, Bradley KA. 2009. Anthrax lethal toxin induced lysosomal membrane permeabilization and cytosolic cathepsin release is Nlrp1b/Nalp1b-dependent. PLoS ONE 4: e7913.

Bird PI, Trapani JA, Villadangos JA. 2009. Endolysosomal proteases and their inhibitors in immunity. Nat Rev Immunol 9: 871-882.

Blomgran R, Zheng L, Stendahl O. 2007. Cathepsin-cleaved Bid promotes apoptosis in human neutrophils via oxidative stress-induced lysosomal membrane permeabilization. J Leukoc Biol 81: 1213-1223.

Blott EJ, Griffiths GM. 2002. Secretory lysosomes. Nat Rev Mol Cell Biol 3: 122-131.

Boya P, Andreau K, Poncet D, Zamzami N, Perfettini JL, Metivier D, Ojcius DM, Jaattela M, Kroemer G. 2003a. Lysosomal membrane permeabilization induces cell death in a mitochondrion-dependent fashion. $J$ Exp Med 197: 1323-1334.

Boya P, Gonzalez-Polo RA, Poncet D, Andreau K, Vieira HL, Roumier T, Perfettini JL, Kroemer G. 2003b. Mitochondrial membrane permeabilization is a critical step of lysosome-initiated apoptosis induced by hydroxychloroquine. Oncogene 22: 3927-3936.

Boya P, Gonzalez-Polo RA, Casares N, Perfettini JL, Dessen P, Larochette N, Metivier D, Meley D, Souquere S, Yoshimori T, et al. 2005. Inhibition of macroautophagy triggers apoptosis. Mol Cell Biol 25: 1025-1040.

Bright NA, Reaves BJ, Mullock BM, Luzio JP. 1997. Dense core lysosomes can fuse with late endosomes and are reformed from the resultant hybrid organelles. J Cell Sci 110: $2027-2040$

Butor C, Griffiths G, Aronson NN Jr, Varki A. 1995. Colocalization of hydrolytic enzymes with widely disparate $\mathrm{pH}$ optima: Implications for the regulation of lysosomal pH. J Cell Sci 108: 2213-2219.

Chen QY, Shi JG, Yao QH, Jiao DM, Wang YY, Hu HZ, Wu YQ, Song J, Yan J, Wu LJ. 2012. Lysosomal membrane permeabilization is involved in curcumin-induced apoptosis of A549 lung carcinoma cells. Mol Cell Biochem 359: $389-398$

Cirman T, Orešič K, Mazovec GD, Turk V, Reed JC, Myers RM, Salvesen GS, Turk B. 2004. Selective disruption of lysosomes in HeLa cells triggers apoptosis mediated by cleavage of Bid by multiple papain-like lysosomal cathepsins. J Biol Chem 279: 3578-3587.

Clark R, Griffiths GM. 2003. Lytic granules, secretory lysosomes and disease. Curr Opin Immunol 15: 516-521.

Conus S, Simon HU. 2008. Cathepsins: Key modulators of cell death and inflammatory responses. Biochem Pharmacol 76: 1374-1382.

Conus S, Perozzo R, Reinheckel T, Peters C, Scapozza L, Yousefi S, Simon HU. 2008. Caspase-8 is activated by cathepsin D initiating neutrophil apoptosis during the resolution of inflammation. J Exp Med 205: 685-698.

Cuervo AM. 2004. Autophagy: Many paths to the same end. Mol Cell Biochem 263: 55-72.

Cuervo AM, Dice JF. 1996. A receptor for the selective uptake and degradation of proteins by lysosomes. Science 273: 501-503. 
U. Repnik et al.

de Duve C. 1959. Subcellular particles (ed. Hayashi T), pp. 128-159. The Ronald Press, New York.

de Duve C, Pressman BC, Gianetto R, Wattiaux R, Appelmans F. 1955. Tissue fractionation studies. 6. Intracellular distribution patterns of enzymes in rat-liver tissue. Biochem J 60: 604-617.

de Duve C, de Barsy T, Poole B, Trouet A, Tulkens P, Van Hoof F. 1974. Lysosomotropic agents. Biochem Pharmacol 23: 2495-2531.

Denamur S, Tyteca D, Marchand-Brynaert J, Van Bambeke F, Tulkens PM, Courtoy PJ, Mingeot-Leclercq MP. 2011. Role of oxidative stress in lysosomal membrane permeabilization and apoptosis induced by gentamicin, an aminoglycoside antibiotic. Free Radic Biol Med 51: $1656-1665$.

DiFranco KM, Gupta A, Galusha LE, Perez J, Nguyen TV, Fineza CD, Kachlany SC. 2012. Leukotoxin (Leukothera $\left.{ }^{\circledR}\right)$ targets active leukocyte function antigen-1 (LFA-1) protein and triggers a lysosomal mediated cell death pathway. J Biol Chem 287: 17618-17627.

Droga-Mazovec G, Bojic L, Petelin A, Ivanova S, Romih R, Repnik U, Salvesen GS, Stoka V, Turk V, Turk B. 2008. Cysteine cathepsins trigger caspase-dependent cell death through cleavage of Bid and antiapoptotic Bcl-2 homologues. J Biol Chem 283: 19140-19150.

Eskelinen EL, Reggiori F, Baba M, Kovacs AL, Seglen PO. 2011. Seeing is believing: The impact of electron microscopy on autophagy research. Autophagy 7: 935-956.

Fehrenbacher N, Bastholm L, Kirkegaard-Sorensen T, Rafn B, Bottzauw T, Nielsen C, Weber E, Shirasawa S Kallunki T, Jaattela M. 2008. Sensitization to the lysosomal cell death pathway by oncogene-induced downregulation of lysosome-associated membrane proteins 1 and 2. Cancer Res 68: 6623-6633.

Feofanov AV, Sharonov GV, Astapova MV, Rodionov DI, Utkin YN, Arseniev AS. 2005. Cancer cell injury by cytotoxins from cobra venom is mediated through lysosomal damage. Biochem J 390: 11-18.

Filicko-O'Hara J, Grosso D, Flomenberg PR, Friedman TM, Brunner J, Drobyski W, Ferber A, Kakhniashvili I, KeeverTaylor C, Mookerjee B, et al. 2009. Antiviral responses following L-leucyl-L-leucine methyl esther (LLME)treated lymphocyte infusions: Graft-versus-infection without graft-versus-host disease. Biol Blood Marrow Transplant 15: 1609-1619.

Friedman TM, Filicko-O’Hara J, Mookerjee B, Wagner JL, Grosso DA, Flomenberg N, Korngold R. 2007. T cell repertoire complexity is conserved after LLME treatment of donor lymphocyte infusions. Biol Blood Marrow Transplant 13: 1439-1447.

Gil-Parrado S, Fernandez-Montalvan A, Assfalg-Machleidt I, Popp O, Bestvater F, Holloschi A, Knoch TA, Auerswald EA, Welsh K, Reed JC, et al. 2002. Ionomycin-activated calpain triggers apoptosis. A probable role for Bcl-2 family members. J Biol Chem 277: 2721727226.

Gonzalez P, Mader I, Tchoghandjian A, Enzenmuller S, Cristofanon S, Basit F, Debatin KM, Fulda S. 2012. Impairment of lysosomal integrity by B10, a glycosylated derivative of betulinic acid, leads to lysosomal cell death and converts autophagy into a detrimental process. Cell Death Differ 19: 1337-1346.
Griffiths G. 1996. On vesicles and membrane compartments. Protoplasma 195: 37-58.

Griffiths G, Hoflack B, Simons K, Mellman I, Kornfeld S. 1988. The mannose 6-phosphate receptor and the biogenesis of lysosomes. Cell 52: 329-341.

Griffiths G, Hollinshead R, Hemmings BA, Nigg EA. 1990a. Ultrastructural localization of the regulatory (RII) subunit of cyclic AMP-dependent protein kinase to subcellular compartments active in endocytosis and recycling of membrane receptors. J Cell Sci 96: 691-703.

Griffiths G, Matteoni R, Back R, Hoflack B. 1990b. Characterization of the cation-independent mannose 6-phosphate receptor-enriched prelysosomal compartment in NRK cells. J Cell Sci 95: 441-461.

Groth-Pedersen L, Jaattela M. 2010. Combating apoptosis and multidrug resistant cancers by targeting lysosomes. Cancer Lett doi: 10.1016/j.canlet.2010.05.021.

Gruenberg J, van der Goot FG. 2006. Mechanisms of pathogen entry through the endosomal compartments. Nat Rev Mol Cell Biol 7: 495-504.

Gyrd-Hansen M, Farkas T, Fehrenbacher N, Bastholm L, Hoyer-Hansen M, Elling F, Wallach D, Flavell R, Kroemer G, Nylandsted J, et al. 2006. Apoptosome-independent activation of the lysosomal cell death pathway by caspase-9. Mol Cell Biol 26: 7880-7891.

Hafner Česen M, Pegan K, Špes A, Turk B. 2012. Lysosomal pathways to cell death and their therapeutic applications. Exp Cell Res 318: 1245-1251.

Hayashi MA, Nascimento FD, Kerkis A, Oliveira V, Oliveira EB, Pereira A, Radis-Baptista G, Nader HB, Yamane T, Kerkis I, et al. 2008. Cytotoxic effects of crotamine are mediated through lysosomal membrane permeabilization. Toxicon 52: 508-517.

Heinrich M, Neumeyer J, Jakob M, Hallas C, Tchikov V, Winoto-Morbach S, Wickel M, Schneider-Brachert W, Trauzold A, Hethke A, et al. 2004. Cathepsin D links TNF-induced acid sphingomyelinase to Bid-mediated caspase-9 and -3 activation. Cell Death Differ 11: 550563.

Hornick JR, Vangveravong S, Spitzer D, Abate C, Berardi F, Goedegebuure P, Mach RH, Hawkins WG. 2012. Lysosomal membrane permeabilization is an early event in $\sigma 2$ receptor ligand mediated cell death in pancreatic cancer. J Exp Clin Cancer Res 31: 41.

Horvath I, Vigh L. 2010. Cell biology: Stability in times of stress. Nature 463: 436-438.

Hou W, Han J, Lu C, Goldstein LA, Rabinowich H. 2010. Autophagic degradation of active caspase-8: A crosstalk mechanism between autophagy and apoptosis. Autophagy 6: 891-900.

Huotari J, Helenius A. 2011. Endosome maturation. EMBO J 30: 3481-3500.

Huynh KK, Eskelinen EL, Scott CC, Malevanets A, Saftig P, Grinstein S. 2007. LAMP proteins are required for fusion of lysosomes with phagosomes. EMBO J 26: 313-324.

Ishisaka R, Utsumi K, Utsumi T. 2002. Involvement of lysosomal cysteine proteases in hydrogen peroxide-induced apoptosis in HL-60 cells. Biosci Biotechnol Biochem 66: $1865-1872$. 
Kagedal K, Zhao M, Svensson I, Brunk UT. 2001. Sphingosine-induced apoptosis is dependent on lysosomal proteases. Biochem J 359: 335-343.

Kagedal K, Johansson AC, Johansson U, Heimlich G, Roberg K, Wang NS, Jurgensmeier JM, Ollinger K. 2005. Lysosomal membrane permeabilization during apoptosis-involvement of Bax? Int J Exp Pathol 86: 309-321.

Kirkegaard T, Roth AG, Petersen NH, Mahalka AK, Olsen OD, Moilanen I, Zylicz A, Knudsen J, Sandhoff K, Arenz C, et al. 2010. Hsp70 stabilizes lysosomes and reverts Niemann-Pick disease-associated lysosomal pathology. Nature 463: 549-553.

Kreuzaler P, Watson CJ. 2012. Killing a cancer: What are the alternatives? Nat Rev Cancer doi: 10.1038/nrc3264.

Kreuzaler PA, Staniszewska AD, Li W, Omidvar N, Kedjouar B, Turkson J, Poli V, Flavell RA, Clarkson RW, Watson CJ. 2011. Stat3 controls lysosomal-mediated cell death in vivo. Nat Cell Biol 13: 303-309.

Kronke M. 1999. Biophysics of ceramide signaling: Interaction with proteins and phase transition of membranes. Chem Phys Lipids 101: 109-121.

Kundra R, Kornfeld S. 1999. Asparagine-linked oligosaccharides protect Lamp-1 and Lamp-2 from intracellular proteolysis. J Biol Chem 274: 31039-31046.

Kurz T, Terman A, Brunk UT. 2007. Autophagy, ageing and apoptosis: The role of oxidative stress and lysosomal iron. Arch Biochem Biophys 462: 220-230.

Li W, Yuan X, Nordgren G, Dalen H, Dubowchik GM, Firestone RA, Brunk UT. 2000. Induction of cell death by the lysosomotropic detergent MSDH. FEBS Lett 470: 35-39.

Lin Y, Epstein DL, Liton PB. 2010. Intralysosomal iron induces lysosomal membrane permeabilization and cathepsin D-mediated cell death in trabecular meshwork cells exposed to oxidative stress. Invest Ophthalmol Vis Sci 51: 6483-6495.

Liu L, Zhang Z, Xing D. 2011. Cell death via mitochondrial apoptotic pathway due to activation of Bax by lysosomal photodamage. Free Radic Biol Med 51: 53-68.

Ludwig AK, Giebel B. 2012. Exosomes: Small vesicles participating in intercellular communication. Int J Biochem Cell Biol 44: 11-15.

Luzio JP, Rous BA, Bright NA, Pryor PR, Mullock BM, Piper RC. 2000. Lysosome-endosome fusion and lysosome biogenesis. J Cell Sci 113: 1515-1524.

Maxfield FR, Yamashiro DJ. 1987. Endosome acidification and the pathways of receptor-mediated endocytosis. $A d v$ Exp Med Biol 225: 189-198.

Mayers JR, Audhya A. 2012. Vesicle formation within endosomes: An ESCRT marks the spot. Commun Integr Biol 5: $50-56$.

Medina DL, Fraldi A, Bouche V, Annunziata F, Mansueto G, Spampanato C, Puri C, Pignata A, Martina JA, Sardiello $\mathrm{M}$, et al. 2011. Transcriptional activation of lysosomal exocytosis promotes cellular clearance. Dev Cell 21: $421-430$.

Melo FR, Lundequist A, Calounova G, Wernersson S, Pejler G. 2011. Lysosomal membrane permeabilization induces cell death in human mast cells. Scand J Immunol 74: $354-362$.
Miller DK, Griffiths E, Lenard J, Firestone RA. 1983. Cell killing by lysosomotropic detergents. J Cell Biol 97: 1841-1851.

Oberle C, Huai J, Reinheckel T, Tacke M, Rassner M, Ekert PG, Buellesbach J, Borner C. 2010. Lysosomal membrane permeabilization and cathepsin release is a Bax/Bak-dependent, amplifying event of apoptosis in fibroblasts and monocytes. Cell Death Differ 17: 11671178.

Ostenfeld MS, Fehrenbacher N, Hoyer-Hansen M, Thomsen C, Farkas T, Jaattela M. 2005. Effective tumor cell death by $\sigma 2$ receptor ligand siramesine involves lysosomal leakage and oxidative stress. Cancer Res 65: 8975-8983.

Pillay CS, Elliott E, Dennison C. 2002. Endolysosomal proteolysis and its regulation. Biochem J 363: 417-429.

Pourahmad J, Hosseini MJ, Eskandari MR, Shekarabi SM, Daraei B. 2010. Mitochondrial/lysosomal toxic crosstalk plays a key role in cisplatin nephrotoxicity. Xenobiotica 40: 763-771.

Ravikumar B, Berger Z, Vacher C, O'Kane CJ, Rubinsztein DC. 2006. Rapamycin pre-treatment protects against apoptosis. Hum Mol Genet 15: 1209-1216.

Repnik U, Stoka V, Turk V, Turk B. 2012. Lysosomes and lysosomal cathepsins in cell death. Biochim Biophys Acta 1824: $22-33$.

Repnik U, Turk B. 2010. Lysosomal-mitochondrial crosstalk during cell death. Mitochondrion 10: 662-669.

Rudolf E, Cervinka M. 2011. Sulforaphane induces cytotoxicity and lysosome- and mitochondria-dependent cell death in colon cancer cells with deleted p53. Toxicol In Vitro 25: 1302-1309.

Saftig P, Klumperman J. 2009. Lysosome biogenesis and lysosomal membrane proteins: Trafficking meets function. Nat Rev Mol Cell Biol 10: 623-635.

Sahara S, Yamashima T. 2010. Calpain-mediated Hsp70.1 cleavage in hippocampal CA1 neuronal death. Biochem Biophys Res Commun 393: 806-811.

Schrader K, Huai J, Jockel L, Oberle C, Borner C. 2010. Noncaspase proteases: Triggers or amplifiers of apoptosis? Cell Mol Life Sci 67: 1607-1618.

Schroder BA, Wrocklage C, Hasilik A, Saftig P. 2010. The proteome of lysosomes. Proteomics 10: 4053-4076.

Stoka V, Turk B, Schendel SL, Kim TH, Cirman T, Snipas SJ, Ellerby LM, Bredesen D, Freeze H, Abrahamson M, et al. 2001. Lysosomal protease pathways to apoptosis. Cleavage of Bid, not pro-caspases, is the most likely route. J Biol Chem 276: 3149-3157.

Terman A, Kurz T, Gustafsson B, Brunk UT. 2006. Lysosomal labilization. IUBMB Life 58: 531-539.

Thelen M, Damme M, Schweizer M, Hagel C, Wong AM, Cooper JD, Braulke T, Galliciotti G. 2012. Disruption of the autophagy-lysosome pathway is involved in neuropathology of the nclf mouse model of neuronal ceroid lipofuscinosis. PLoS ONE 7: e35493.

Thiele DL, Lipsky PE. 1990. Mechanism of L-leucyl-L-leucine methyl ester-mediated killing of cytotoxic lymphocytes: Dependence on a lysosomal thiol protease, dipeptidyl peptidase I, that is enriched in these cells. Proc Natl Acad Sci 87: 83-87. 
U. Repnik et al.

Tjelle TE, Brech A, Juvet LK, Griffiths G, Berg T. 1996. Isolation and characterization of early endosomes, late endosomes and terminal lysosomes: Their role in protein degradation. J Cell Sci 109: 2905-2914.

Trapani JA, Smyth MJ. 2002. Functional significance of the perforin/granzyme cell death pathway. Nat Rev Immunol 2: 735-747.

Turk B, Turk V. 2009. Lysosomes as "suicide bags" in cell death: Myth or reality? J Biol Chem 284: 21783-21787.

Turk B, Stoka V, Rozman-Pungerčar J, Cirman T, DrogaMazovec G, Orešič K, Turk V. 2002. Apoptotic pathways: Involvement of lysosomal proteases. Biol Chem 383: 1035-1044.

Turk B, Turk D, Turk V. 2012. Protease signalling: The cutting edge. EMBO J 31: 1630-1643.

Vanden Berghe T, Vanlangenakker N, Parthoens E, Deckers W, Devos M, Festjens N, Guerin CJ, Brunk UT, Declercq W, Vandenabeele P. 2010. Necroptosis, necrosis and secondary necrosis converge on similar cellular disintegration features. Cell Death Differ 17: 922-930.

Vanlangenakker N, Vanden Berghe T, Krysko DV, Festjens N, Vandenabeele P. 2008. Molecular mechanisms and pathophysiology of necrotic cell death. Curr Mol Med 8: 207-220.

Wang Y, Singh R, Massey AC, Kane SS, Kaushik S, Grant T, Xiang Y, Cuervo AM, Czaja MJ. 2008. Loss of macroautophagy promotes or prevents fibroblast apoptosis depending on the death stimulus. J Biol Chem 283: 47664777.

Werneburg NW, Guicciardi ME, Bronk SF, Gores GJ. 2002. Tumor necrosis factor- $\alpha$-associated lysosomal permeabilization is cathepsin B dependent. Am J Physiol Gastrointest Liver Physiol 283: G947-G956.
Werneburg NW, Guicciardi ME, Bronk SF, Kaufmann SH, Gores GJ. 2007. Tumor necrosis factor-related apoptosisinducing ligand activates a lysosomal pathway of apoptosis that is regulated by Bcl-2 proteins. J Biol Chem 282: 28960-28970.

Werneburg NW, Bronk SF, Guicciardi ME, Thomas L, Dikeakos JD, Thomas G, Gores GJ. 2012. Tumor necrosis factor-related apoptosis inducing ligand (TRAIL) induced lysosomal translocation of proapoptotic effectors is mediated by phosphofurin acidic cluster sorting protein-2 (PACS-2). J Biol Chem 287: 24427-24437.

Wilson PD, Firestone RA, Lenard J. 1987. The role of lysosomal enzymes in killing of mammalian cells by the lysosomotropic detergent $\mathrm{N}$-dodecylimidazole. J Cell Biol 104: $1223-1229$.

Yamashima T. 2012. Hsp70.1 and related lysosomal factors for necrotic neuronal death. J Neurochem 120: 477-494.

Yu L, McPhee CK, Zheng L, Mardones GA, Rong Y, Peng J, Mi N, Zhao Y, Liu Z, Wan F, et al. 2010. Termination of autophagy and reformation of lysosomes regulated by mTOR. Nature 465: 942-946.

Yue XL, Lehri S, Li P, Barbier-Chassefiere V, Petit E, Huang QF, Albanese P, Barritault D, Caruelle JP, PapyGarcia D, et al. 2009. Insights on a new path of pre-mitochondrial apoptosis regulation by a glycosaminoglycan mimetic. Cell Death Differ 16: 770-781.

Zhao M, Brunk UT, Eaton JW. 2001. Delayed oxidant-induced cell death involves activation of phospholipase A2. FEBS Lett 509: 399-404.

Zhao M, Antunes F, Eaton JW, Brunk UT. 2003. Lysosomal enzymes promote mitochondrial oxidant production, cytochrome $c$ release and apoptosis. Eur J Biochem 270: $3778-3786$. 


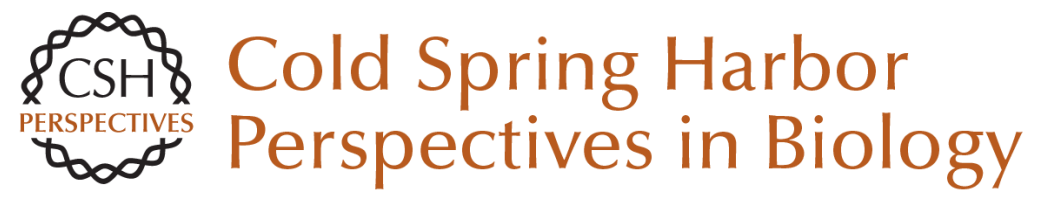

\section{The Endolysosomal System in Cell Death and Survival}

Urska Repnik, Marusa Hafner Cesen and Boris Turk

Cold Spring Harb Perspect Biol 2013; doi: 10.1101/cshperspect.a008755

Subject Collection Cell Survival and Cell Death

Programmed Cell Death in the Evolutionary Race against Bacterial Virulence Factors

Carolyn A. Lacey and Edward A. Miao

The Evolutionary Origins of Programmed Cell

Death Signaling

Kay Hofmann

Regulation of Cell Death and Immunity by XIAP Philipp J. Jost and Domagoj Vucic

Dysregulation of Cell Death in Human Chronic Inflammation

Yue Li, Christoph Klein and Daniel Kotlarz

Cell Death in Plant Immunity

Eugenia Pitsili, Ujjal J. Phukan and Nuria S. Coll

Recent Insights on Inflammasomes, Gasdermin Pores, and Pyroptosis

Nathalia M. de Vasconcelos and Mohamed Lamkanfi

Phagocyte Responses to Cell Death in Flies Andrew J. Davidson and Will Wood

Mechanism and Regulation of

Gasdermin-Mediated Cell Death

Shiyu Xia, Louis Robert Hollingsworth IV and Hao Wu
Cell Death and Neurodegeneration Benjamin J. Andreone, Martin Larhammar and Joseph W. Lewcock

Death Receptors and Their Ligands in Inflammatory Disease and Cancer Alessandro Annibaldi and Henning Walczak

The Killer Pseudokinase Mixed Lineage Kinase Domain-Like Protein (MLKL) James M. Murphy

Neutrophil Extracellular Traps in Host Defense Sabrina Sofia Burgener and Kate Schroder

Cell-Cycle Cross Talk with Caspases and Their Substrates Patrick Connolly, Irmina Garcia-Carpio and Andreas Villunger

Cracking the Cell Death Code Carla V. Rothlin and Sourav Ghosh

BAX, BAK, and BOK: A Coming of Age for the BCL-2 Family Effector Proteins

Tudor Moldoveanu and Peter E. Czabotar

Multitasking Kinase RIPK1 Regulates Cell Death and Inflammation

Kim Newton

For additional articles in this collection, see http://cshperspectives.cshlp.org/cgi/collection/

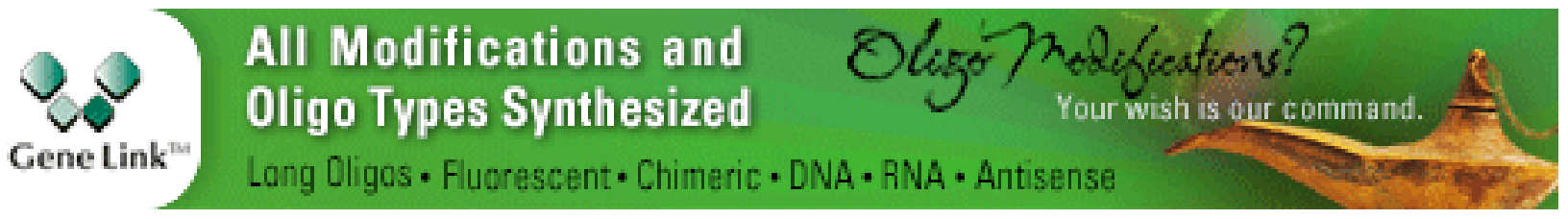

Copyright @ 2013 Cold Spring Harbor Laboratory Press; all rights reserved 
For additional articles in this collection, see http://cshperspectives.cshlp.org/cgi/collection/

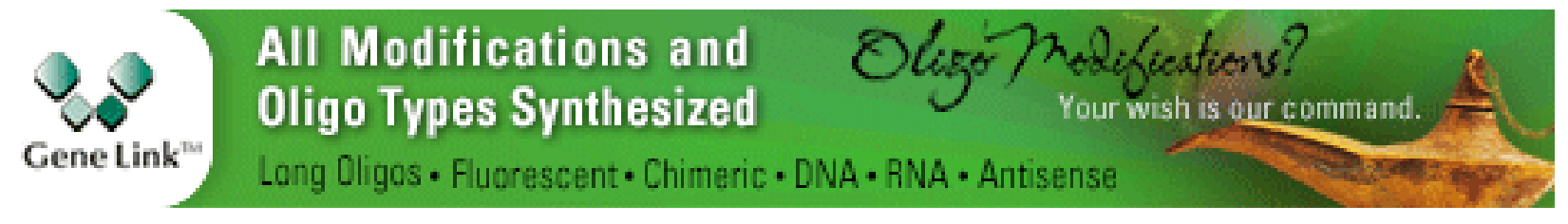

Copyright @ 2013 Cold Spring Harbor Laboratory Press; all rights reserved 